\title{
The corrected QT interval prolongation in adolescents with cardiac iron overload $\beta$-thalassemia major
}

\author{
Najib Advani ${ }^{\oplus}$, Ahmad Kautsar ${ }^{\oplus}$, Murti Andriastuti ${ }^{\odot}$ \\ Department of Child Health, Faculty of Medicine Universitas Indonesia-Cipto Mangunkusumo Hospital, Jakarta, Indonesia.
}

\begin{abstract}
Background and objectives. Iron-induced cardiomyopathy remains the leading cause of mortality in $\beta$-thalassemia major patients. The $\mathrm{T}^{*}$ magnetic resonance imaging (MRI) technique is the gold standard for iron load detection, yet it is expensive and not widely available especially in the developing countries. Some previous studies showed that QTc interval could be used as an early detection of cardiac iron overload. This study aimed to evaluate the diagnostic value of QTc interval as a marker of early detection of cardiac iron overload in adolescent beta thalassemia major patients.
\end{abstract}

Methods. We prospectively evaluated electrocardiography (ECG) parameter of QTc interval in $50 \beta$-thalassemia major patients aged 10-18 years. All participants had a 12-lead ECG evaluation, echocardiogram and cardiac MRI T2* examination within three months (average 15 days). They were categorized as cardiac iron overload (MRI T2* $<20$ millisecond) and non-cardiac iron overload (MRI T2* $>20$ millisecond).

Results. Of the 50 patients, the male to female ratio was 1.08:1 and the mean age was $13.7 \pm 2.43$ years. All participants showed normal systolic and diastolic function using conventional echocardiography. The mean QTc interval was significantly different between cardiac iron overload group (464.44 $\pm 20.35 \mathrm{~ms})$ and noncardiac iron overload group $(431.09 \pm 32.29)(\mathrm{p}=0.001)$. Diagnostic study of QTc interval resulted in AUC $0.8(\mathrm{p}=$ 0.002). Calculated sensitivity and specificity of QTc interval were 0.88 and 0.73 respectively, with cut-off point of $449 \mathrm{~ms}$.

Conclusion. Cardiac iron overload is associated with QTc prolongation in adolescents. QTc interval of $449 \mathrm{~ms}$ could be considered as a cut-off point of cardiac iron overload.

Key words: adolescent, $\beta$ - thalassemia major, cardiac MRI T2*, QTc interval.

Thalassemia is the most prevalent single gene-disorder which has $4.5 \%$ prevalence of carrier gene and 300.000-500.000 homozygotes born each year. ${ }^{1}$ Regular blood transfusion is inevitable in beta thalassemia major due to its nature of chronic hemolysis and impose the risk of having iron overload. ${ }^{2}$ Routine blood transfusion in addition to increase of intestinal iron absorption will lead to iron loading in many organs. ${ }^{2,3}$ Iron overload or in combination with immunogenetic factors will lead to the development of cardiomyopathy

$\triangle \quad$ Najib Advani

najib.advani@gmail.com

Received 20th December 2018, revised 17th March 2019, 10th June 2019, accepted 20th September 2019. in beta-thalassemia major. ${ }^{4-6}$ Despite the advances in iron chelating agent, iron overload cardiomyopathy remains the most important cause of mortality and morbidity.-9 Hence, it is of utmost important to detect iron overload early as adequate agent could reverse the disease process. ${ }^{10-12}$

Echocardiography study is the standard monitoring of cardiac function in thalassemia patients yet systolic and diastolic dysfunction are late signs. ${ }^{13,14}$ Rhythm monitoring using 12lead electrocardiography (ECG) was previously considered nonspecific although recent metaanalysis of case control studies has proven otherwise. ${ }^{15-17}$ Cardiac magnetic resonance imaging T2-star (T2*) is currently becoming the gold standard of cardiac iron overload 
evaluation and has a good correlation with cardiac iron concentration. ${ }^{18-20}$ However, it is quite expensive and not widely available in the developing countries.

The incidence of QT prolongation and sudden cardiac death are increased among thalassemia major patients. ${ }^{21-30} \mathrm{~A}$ previous study revealed that increased iron stores are associated with QT prolongation independent of hemochromatosis genotype and inflammation. ${ }^{17}$ Therefore, we evaluated the current literature to evaluate the association of QTc interval prolongation and cardiac iron loading. However, to the best of our knowledge there is no such study done exclusively in the adolescent group. The aim of this study was to determine the use of QTc interval prolongation in adolescent beta-thalassemia major to detect cardiac hemosiderosis assessed by MRI T2*.

\section{Material and Methods}

\section{Study population}

Fifty adolescent patients, aged 10-18 years (27 males, 23 females) with $\beta$-thalassemia major were enrolled in this study during June until November 2017. Inclusion criteria were asymptomatic $\beta$-thalassemia major patients with pre-transfusion hemoglobin level above 7 $\mathrm{g} / \mathrm{dl}$. Patients with clinical sign and symptoms of heart failure, impaired renal and liver function were excluded. All subjects were receiving regular blood transfusions every 2-3 weeks and chelation therapy, which was started before the age of 5 years. At the time of MRI examination, 32 patients were receiving deferiprone (DFP) chelation therapy, 8 deferasirox (DFX), 4 combination therapy of DFP and DFX, 3 combination therapy of DFP and deferoxamine (DFO), and 3 combination therapy of DFP and DFX.

All subjects were evaluated for 12-lead electrocardiography and echocardiography within 3 months after cardiac MRI T2* examination. The local ethics committee approved the study protocol (decision number 424 , dated may $8^{\text {th }}, 2017$ ) and written informed consent was obtained from all patients and/or parents.

\section{Ferritin measurement}

Ferritin levels were determined by an electrochemiluminescence technique using the Roche e 411 Cobas immunoassay analyzer (Roche Diagnostics). The mean serum ferritin value was derived from the mean obtained at 3-months interval over the previous year.

\section{Cardiac iron concentration}

T2* MRI examination was performed by 1.5 Tesla MRI scanner (Siemens Avanto Germany). Myocardial T2* was analyzed using dedicated software (Thalassemia-Tools; Cardiovascular Imaging Solutions, London, United Kingdom) with regions of interest in ventricular septum. Each image was acquired during 11-13 s breath-hold, using a gradient echocardiogram sequence. The repetition time was 200 millisecond, the flip angle used was $20^{\circ}$, echo times was $1.3-23 \mathrm{~ms}$, the base resolution matrix was 128 pixels, the field of view was $39.7 \mathrm{~cm}$ and $19.7 \mathrm{~cm}$, and the sampling bandwidth was 125 $\mathrm{kHz}$. Results of cardiac $\mathrm{T}^{*}$ were categorized as severe $\left(\mathrm{T} 2^{*}<10 \mathrm{~ms}\right)$, mild to moderate $(10 \mathrm{~ms}$ $<\mathrm{T} 2^{*}<20 \mathrm{~ms}$ ), and acceptable (T2* $>20 \mathrm{~ms}$ ). All investigators involved in the study were blind of any information regarding patient's medical records.

\section{Echocardiography}

Systolic function (fractional shortening and ejection fraction) and diastolic function (ratio of the Early (E) to late (A) ventricular filling velocity) were recorded. Normal left systolic function was defined as ejection fraction between $56 \%-78 \%$ and fraction shortening between 28\%-44\%; while normal diastolic function was defined as E/A ratio $1.9 \pm 0.5 .^{31}$ Normal right ventricular systolic function was defined as tricuspid annular plane systolic excursion (TAPSE) $>16 \mathrm{~mm} \cdot{ }^{32}$ 


\section{ECG Measurement}

We performed 12-lead ECG examinations on all subjects with speed set at $25 \mathrm{~mm} /$ second and gain at $10 \mathrm{~mm} / \mathrm{mV}$. The ECG was scanned and interpreted manually blinded to the MRI results. Conduction parameters, including PR, QRS, and QT intervals were measured from the average of three consecutive beats mostly in lead II. The QT interval were measured from the start of QRS complex until the end of T wave. The end of QT interval was selected using tangential method. ${ }^{26}$ Correction of QT interval for heart rate was calculated using Bazett's formula (QTc $=\mathrm{QT} / \sqrt{ } \mathrm{RR})$. All interval measurements were presented in milliseconds. ECG was measured prior to cardiac MRI examination.

\section{Statistical analysis}

All tests were carried out using SPSS (Statistical Package for Social Sciences) version 23 software ( IBM Corp., NY, USA). Sample size was calculated using formula for comparing two independet means. Data are expressed as mean \pm standard deviation as indicated. SaphiroWilk test was performed for testing normality. Statistically significant differences between two groups of continous variables were determined by using independent $\mathrm{t}$-test or Mann-Whitney test as appropriate. Diagnostic study and cutoff were set using receiver operating curve analysis. A P-value $<0.05$ was considered statistically significant.

\section{Results}

Subjects comprised of 50 patients (mean age $13.7 \pm 2.43$ years, $54 \%[n=27]$ male, $46 \%$ $[\mathrm{n}=23]$ female) with transfusion dependent $\beta$-thalassemia major. Patient's demographic and baseline characteristics are presented in Table I. There were $41(82 \%)$ patients without evidence of cardiac hemosiderosis ( $\mathrm{T}^{*}>20$ $\mathrm{ms})$, while $9(18 \%)$ had cardiac hemosiderosis, $\left(\mathrm{T}^{*}<20 \mathrm{~ms}\right)$, of whom 2 had severe cardiac hemosiderosis $\left(\mathrm{T}^{*}<10 \mathrm{~ms}\right.$ ). Mean ferritin serum levels were increased in patients with cardiac hemosiderosis $(5185 \pm 2247 \mathrm{ng} / \mathrm{ml})$ compared
Table I. Baseline characteristics of patients.

\begin{tabular}{lc}
\hline Characteristics & $\mathrm{n}=50$ \\
\hline Gender $\mathrm{n}(\%)$ & $27(54)$ \\
$\quad$ Male & $23(46)$ \\
$\quad$ Female & $13.71 \pm 2.43$ \\
Age, mean \pm SD, years & $8.19 \pm 8.24$ \\
Age at diagnosis, mean \pm SD, months & $33.07 \pm 10.05$ \\
Body weight, mean \pm SD, kg & $16 \pm 3.7$ \\
Frequency of transfusion/year, mean \pm & \\
SD, times/years & $9 \pm 1.32$ \\
Pre-transfusion Hb, mean \pm SD, g/dl & \\
Chelation & \\
Monotherapy & $32(64 \%)$ \\
$\quad$ DFP & $8(16 \%)$ \\
$\quad$ DFX & \\
Combination & $4(8 \%)$ \\
$\quad$ DFP+DFX & $3(6 \%)$ \\
DFP+DFO & $3(6 \%)$ \\
DFO+DFX &
\end{tabular}

SD: Standard deviation, DFP: deferipron, DFX: desferoxamine, DFO: desferral.

to non-siderosis $(4339 \pm 2011 \mathrm{ng} / \mathrm{ml})$ but it was statistically not significant $(\mathrm{p}=0.32)$.

Echocardiography examination of all patients revealed no abnormalities either in systolic or diastolic parameters as shown in Table II. Of all assessed ECG parameters, only mean QTC interval showed significant difference between cardiac iron overload $(\mathrm{CIO})$ and no-CIO groups $(p=0.001)$ (Table III). We could not find other causes of long QTc in subjects with prolonged QTc. Further ROC analysis of QTc interval demonstrated an area under curve (AUC) value of 0.835 ( $p=0.02$ CI 95\% 0.705-0.965) for the presence of cardiac iron (Fig. 1). The optimal cut-off point of diagnosis $\mathrm{CIO}$ was selected at $449 \mathrm{~ms}$ and yielded a sensitivity of $88.9 \%$ and a specificity of $73.1 \%$. Negative predictive value (NPV) and positive predictive value (PPV) for this value were $42.1 \%$ and $96.7 \%$, respectively.

\section{Discussion}

To our knowledge, this is the first study assessing ECG parameters exclusively done in adolescent 
Table II. Echocardiography results.

\begin{tabular}{lccc}
\hline Echo Results & $\mathrm{T} 2^{*}<20(\mathrm{n}=9)$ & $\mathrm{T} 2^{*}>20(\mathrm{n}=41)$ & $\mathrm{p}$ \\
\hline Left Ventricle Systolic Function & & & $0.53^{\mathrm{a}}$ \\
LVEF, mean \pm SD, $\%$ & $67.2 \pm 6.5$ & $66.03 \pm 6.4$ & $0.92^{\mathrm{a}}$ \\
FS, mean \pm SD, $\%$ & $35.7 \pm 6.7$ & $35.98 \pm 4.99$ & \\
Right Ventricle Systolic Function & & & $0.55^{\mathrm{b}}$ \\
TAPSE, mean \pm SD, mm & $22.64 \pm 2.91$ & $23.54 \pm 4.05$ & \\
$\begin{array}{l}\text { Diastolic Function } \\
\text { E/A, mean } \pm \text { SD }\end{array}$ & $1.78 \pm 0.3$ & $1.7 \pm 0.26$ & $0.48^{\mathrm{a}}$ \\
\hline
\end{tabular}

${ }^{a}$ Mann-whitney test ${ }^{b}$ independent $t$-test

LVEF: Left ventricular ejection fraction, SD: Standard deviation

FS: Fractional shortening, TAPSE: Tricuspid annular plane systolic excursion

E/A: Ratio of the early to late ventricular filling velocity, $\mathrm{mm}$ : millimeter.

Table III. Difference of ECG parameters between CIO and no-CIO patients.

\begin{tabular}{lccc}
\hline ECG Parameters (mean \pm SD) & T2*20 $(\mathrm{n}=9)$ & $\mathrm{T} 2^{*}>20(\mathrm{n}=41)$ & $\mathrm{p}$ \\
\hline Heart Rate, (BPM) & $95 \pm 13$ & $86 \pm 18$ & $0.09^{\mathrm{a}}$ \\
PR Interval (ms) & $134.25 \pm 32.77$ & $147.61 \pm 21.02$ & $0.13^{\mathrm{b}}$ \\
QRS duration (ms) & $77.75 \pm 10.21$ & $78.82 \pm 13.32$ & $0.921^{\mathrm{b}}$ \\
QT Interval (ms) & $417.8 \pm 57$ & $387 \pm 38.4$ & $0.052 \mathrm{a}$ \\
QTc Interval (ms) & $464.44 \pm 20.35$ & $431.09 \pm 32.29$ & $0.001^{\mathrm{a}}$ \\
\hline
\end{tabular}

${ }^{a}$ T-test ${ }^{\mathrm{b}}$ Mann-Whitney Test

BPM: beat per minute, CIO: Cardiac Iron Overload, ms: millisecond.

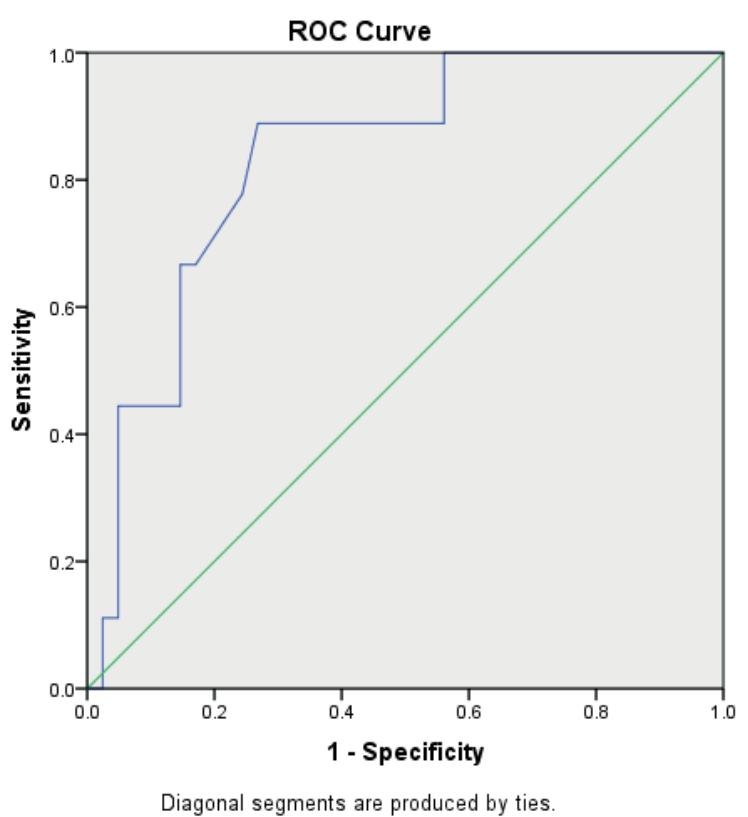

Fig. 1. ROC curve of QTc interval.

$\beta$-thalassemia patients. The most important finding of the present study is the difference of QTc interval in $\mathrm{CIO}$ and no-CIO adolescent $\beta$-thalassemia patients. Furthermore, we demonstrated that QTc interval had relatively good diagnostic value to diagnose CIO.

Patients with iron overload cardiomyopathies experience heart failure with systolic and diastolic dysfunction often in combination with electrical rhythm disturbances, including slowed electrical conduction, heart block, and the increase likelihood of having atrial fibrillation. ${ }^{14,27}$ Iron overload cardiomyopathies are marked by early diastolic dysfunction which precedes systolic dysfunction. . $^{14,27}$ Conventional echocardiography examination in this study was all normal indicating that all patients were at the early stage of the disease.

Electrical rhythm disturbances recorded in $\mathrm{CIO}$ in previous studies are mostly non-specific, typically associated with repolarization abnormalities and relative bradycardia. ${ }^{25}$ QT interval as a mean of identifying depolarization and repolarization abnormalities arehighlighted in our study. Recent meta-analysis showed 
that thalassemia patients have prolonged QT interval compared to healthy controls. ${ }^{17}$ The relationship between QT parameters and iron overload measured by serum ferritin had been studied previously with conflicting results. ${ }^{24,28}$ Ulger et al. $^{28}$ found no correlation of QT parameters (QT interval, QTc interval, and QT dispersions) with serum ferritin levels while Faruqi et al. ${ }^{24}$ showed QT interval, QTc interval, and QT dispersion are prolonged in patients with high serum ferritin level $(>2500 \mathrm{ng} / \mathrm{ml})$. Although serum ferritin was traditionally used as a marker for iron overload, it does not necessarily represent tissue's iron content since its level is influenced by many factors including infections. Furthermore, ferritin level is measured from the blood and not from any organ such as the heart, therefore it may not reveal its real level in the heart. In this study we measured directly focused to the heart by ECG and cardiac MRI, which shows obvious correlation between MRI and ECG results.

Measuring cardiac iron loading has become possible using MRI T2*, and well corellated with cardiac iron loading in vivo. ${ }^{19,20}$ The relationship between electrocardiographic recording and cardiac MRI T2* has been prevously studied. ${ }^{25}$ Detterich et al. ${ }^{25}$ found that repolarization indices were the most sensitive discriminators and QT interval was greater in patients with $\mathrm{CIO} .{ }^{25}$ In our study, mean QT interval was not statistically different but QTc interval was significantly increased in CIO patients. Although Detterich et al. ${ }^{25}$ had also found a significantly longer QTC in patients with detectable cardiac iron they did not exclusively include adolescents. Our study specified in adolescent patients which may or may not be valid for other age groups. Besides QT parameters, other repolarization abnormalities such as ST and $\mathrm{T}$ wave abnormalities may be found in $\mathrm{CIO}$ patients which was not focused in our study. QT prolongation in thalassemia patients may be secondary to compensatory ventricular dilation and increased circulatory oxidative species caused by labile plasma iron. ${ }^{29,30}$ In an animal model, $\mathrm{CIO}$ was characterized by a decrease of the overshoot and duration of action potential and impairment of delayed rectifier potassium channel. ${ }^{33} \mathrm{CIO}$ is also associated with bradycardia which may arise from altered intrinsic sinoatrial node function. ${ }^{34}$ The number of patients with bradycardia was not different between two groups in our study which may be due to small sample size or relatively early stage of the disease.

The relatively good diagnostic value of QTc interval with high sensitivity might lead to the use of QTc interval as a screenig tool. The QTc interval prolongation perhaps could be regarded as a surrogate marker of MRI T2* to detect cardiac iron overload especially in the adolescent group. It is indeed much cheaper, widely available and could be done by the majority of health personnel. It is needed in areas where thalassemia is of high prevalence with limited resources. However, larger sample size and multi center study may be needed to support the results

Cardiac iron overload is associated with QTc prolongation in the adolescent. The QTc interval value of $449 \mathrm{~ms}$ might be used as a cut off point of cardiac iron overload.

\section{REFERENCES}

1. Modell B, Darlison M. Global epidemiology of haemoglobin disorders and derived service indicators. Bull World Health Organ 2008; 86: 480487.

2. Hershko C. Iron loading and its clinical implication. Am J Hematol 2007; 82(Suppl 12): 1147-1148.

3. Martin A, Thompson AA. Thalassemias. Pediatr Clin N Am 2013; 60: 1383-1391.

4. Kremastinos DT, Tiniakos G, Theodorakis GN, Katritsis DG, Toutouzas PK. Myocarditis in beta-thalassemia major. A cause of heart failure. Circulation 1995; 91: 66-71.

5. Kremastinos DT, Flevari P, Spyropoulou M, Vrettou H, Tsiapras D, Stavropoulos-Giokas CG. Association of heart failure in homozygous beta-thalassemia with the major histocompatibility complex. Circulation 1999; 100: 2074-2078. 
6. Economou-Petersen E, Aessopos A, Kladi A, et al. Apolipoprotein E epsilon-4 alelle as a genetic risk factor for left ventricular failure in homozygous thalassemia. Blood 1998; 92: 3455-3459.

7. Modell B, Khan M, Darlison M. Survival in beta thalassemia major in the UK: data from the UK Thalassemia register. Lancet 2000; 355: 2051-2052.

8. Borgna-Pignatti C, Rugolotto S, De Stefano P, et al. Survival and complications in patients with thalassemia major treated with transfusion and deferoxamine. Hematologica 2004; 89: 1187-1193.

9. Felker GM, Thompson RE, Hare JM, et al. Underlying causes and long-term survival in patients with initially unexplained cardiomyopathy. N Engl J Med 2000; 342: 1077-1084.

10. Tanner MA, Galanello R, Dessi C, et al. A randomized, placebo-cotrolled, double-blind trial of the effect of combined therapy with deferoxamine and deferiprone on myocardial iron in thalassemia major using cardiovascular magnetic resonance. Circulation 2007; 115: 1876-1884.

11. Farmaki K, Tzoumari I, Pappa C, Chouliaras G, Berdoukas V. Normalisation of total body iron load with very intensive combined chelation reverses cardiac and endocrine complication of thalassemia major. Br J Haematol 2010; 148: 466-475.

12. Porter JB. Optimizing iron chelation strategies in beta-thalassemia major. Blood Rev 2009; 23(Suppl 1): S3-S7.

13. Davis BA, O'Sullivan C, Jarrit PH, Porter JB. Value of sequential monitoring of left ventricular ejection fraction in the management of thalassemia major. Blood 2004; 104: 263-269.

14. Wood JC, Enriquez C, Ghugre N, et al. Physiology and pathophysiology of iron cardiomyopathy in thalassemia. Ann N Y Acad Sci 2005; 1054: 386-395.

15. De Chiara B, Crivellaro W, Sara R, et al. Early detection of cardiac dysfunction in thalassemic patients by radionuclide angiography and heart rate variability analysis. Eur J Haematol 2005; 74: 517522.

16. Qureshi N, Avasarala K, Foote D, Vichinsky EP. Utility of holter echocardiogram in iron-overloaded hemoglobinopathies. Ann N Y Acad Sci 2005; 1054: 476-480.

17. Henriksen LF, Petri AS, Hasselbach HC, Kanters JK, Ellervik C. Increased iron stores prolong the QT interval-a general population study including 20261 individuals and meta-analysis of thalassemia major. Br J Haematol 2016; 174: 776-785.
18. Anderson LJ, Holden S, Davis B, et al. Cardiovascular T2-star (T2*) magnetic resonance for the early diagnosis of myocardial iron overload. Eur Heart J 2001; 22: 2171-2179.

19. Kirk P, He T, Anderson LJ, et al. International reproducibility of single breathhold $\mathrm{T} 2 * \mathrm{MR}$ for cardiac and liver iron assessment among five thalassemia centers. J Magn Reson Imaging 2010; 32: 315-319.

20. Carpenter JP, He T, Kirk P, et al. On T2* magnetic resonance and cardiac iron. Circulation 2011; 123: 1519-1528.

21. Garadah TS, Kassab S, Mahdi N, Abu-Taleb A, Jamsheer A. QTc interval and QT dispersion in patients with thalassemia major:electrocardiographic (EKG) and echocardiographic evaluation. Clin Med Insights Cardiol 2010; 4: 31-37.

22. Oztarhan K, Delibas Y, Salcioglu Z, et al. Assessment of cardiac parameters in evaluation of cardiac functions in patients with thalassemia major. Pediatr Hematol Oncol 2012; 29: 220-234.

23. Farahani B, Abbasi MA, Khaheshi I, Paydary K. Evaluation of QT interval in $\beta$ thalassemia major patients in comparison with control group. Heart Views 2012; 13: 42-45.

24. Faruqi A, Ahmad SI, Ahmed ST. Evaluation of QT parameters in patients of thalassemia majors with iron overload. J Pak Med Assoc 2016; 66: 799-802.

25. Detterich J, Noetzli L, Dorey F, et al. Electrocardiographic consequences of cardiac iron overload in thalassemia major. Am J Hematol 2012; 87: 139-144.

26. Postema PG, De Jonas SSG, Van der Bilt IAC, Wilde AAM. Accurate electrocardiographic assessment of the QT interval: teach the tangent. Heart Rhythm 2008; 5: 1015-1018.

27. Pennell DJ, Udelson JE, Arai AE, et al; American Heart Association Committee on Heart Failure and Transplantation of the Council on Clinical Cardiology and Council on Cardiovascular Radiology and Imaging. Cardiovascular function and treatment in $\beta$-thalassemia major a consensus statement from the American heart association. Circulation 2013; 128: 281-308.

28. Ulger Z, Aydinok Y, Levent E, Gurses D, Ozyurek AR. Evaluation of QT dispersion in $\beta$ thalassaemia major patients. Am J Hematol 2006; 81: 901-906.

29. Claster S, Wood JC, Noetzli L, et al. Nutritional deficiencies in iron overloaded patients with hemoglobinopathies. Am J Hematol 2009; 84: 344348 . 
30. Westwood MA, Anderson LJ, Maceira AM, et al. Normalized left ventricular volumes and function in thalassemia major patients with normal myocardial iron. J Magn Reson Imaging 2007; 25: 1147-1151.

31. Haas NA, Kleideiter U. Pediatric Cardiology. Stuutgart: Thieme, 2015: 31.

32. Koestenberger $M$, Ravekes E, Everett AD, et al. Right ventricular function in infants, children and adolescents: reference values of the tricuspid annular plane systolic excursion (TAPSE) in 640 healthy patients and calculation of $\mathrm{z}$ score values. J Am Soc Echocardiogr 2009; 22: 715-719.
33. Kuryshev YA, Brittenham GM, Fujioka H, et al Decreased sodium and increased transient outward potassium currents in iron-loaded cardiac myocytes. Implications for the arrhythmogenesis of human siderotic heart disease. Circulation 1999; 100: 675683.

34. Rose RA, Sellan M, Simpson JA, et al. Iron overload decreases CaV1.3-dependent L-type Ca2+ currents leading to bradycardia, altered electrical conduction, and atrial fibrillation. Circ Arrhythm Electrophysiol 2011; 4: 733-742. 